\title{
Crystallization, thermal and mechanical behavior of oligosebacate plasticized poly(lactic acid) films
}

\author{
Erika Martins Inácioㅁ, Maria Celiana Pinheiro Lima², Diego Holanda Saboya Souza1', Lys Sirelli1 and \\ Marcos Lopes Dias ${ }^{1 *}$
}

\author{
${ }^{1}$ Instituto de Macromoléculas Professora Eloisa Mano - IMA, Universidade Federal do Rio de Janeiro - \\ UFRJ, Rio de Janeiro, RJ, Brasil \\ ${ }^{2}$ Instituto Federal do Rio de Janeiro - IFRJ, Duque de Caxias, RJ, Brasil \\ *mldias@ima.ufrj.br
}

\begin{abstract}
The biodegradable aliphatic oligoester oligo(trimethylene separate) (OTS) was synthesized by polycondensation and used to plasticize poly(lactic acid) (PLA). Casting films of PLA and PLA/OTS with concentrations of 1, 5 and 10 wt.\% were prepared, and these films were characterized by thermal analyses, crystallinity, rheology and mechanical tests. DSC revealed the decrease in the $\mathrm{T}$ of PLA films with addition of the oligomer and a partial immiscibility. Addition of OTS to PLA slightly decrease the thermal stability as well as increase the degree of crystallinity of these films. Dynamic-mechanical analyses of casting films showed that the PLA/OTS system presented lower storage modulus than PLA and mechanical test revealed an increased in the elongation at break for PLA films containing the oligoester. The results make possible to conclude that the oligomer synthesized from bio-based monomers acts as a plasticizer of PLA increasing the PLA ductility.
\end{abstract}

Keywords: plasticization poly(lactic acid), oligoesters, trimethylene sebacate, cast films.

\section{Introduction}

Thermoplastics have been increasingly used as packaging materials due to important properties like low density, high mechanical resistance and transparency. The use of conventional plastics has caused increasing concern in relation to the environmental impacts that these materials can generate, due to the degradation time, which can reach hundreds of years ${ }^{[1-4]}$.

For this reason, the scientific community has searched new polymer materials that can decrease the impacts of fossil plastics, with focus in the biodegradable bioplastics ${ }^{[5]}$. Biodegradable plastics are materials in which the degradation occurs initially by the action of microorganisms, like bacteria, fungi and algae, transforming the polymer chains in carbon dioxide, methane, microbial cell components and other products ${ }^{[3]}$. Biodegradation processes can decrease the amount of plastic residue in the environment, since it reduces drastically the degradation time of these materials. Nevertheless, for the biodegradation of a polymer to occur, it must be in an appropriate environment because, if not, biodegradation can equally take place in many years ${ }^{[6]}$.

Aiming for green materials to substitute conventional plastics, different biodegradable plastics has been used, with emphasis in polymers from natural origin obtained by chemical synthesis or microbiological fermentations ${ }^{[4]}$.

Poly(lactic acid) (PLA) is an important biodegradable polymer which can be synthesized by means of condensation of lactic acid or by ring opening polymerization of lactides that are lactic acid dimers. Due to its biodegradability, non-toxicity and good biocompatibility and processability ${ }^{[7]}$, PLA has been largely investigated in studies that aim application as food packaging ${ }^{[8,9]}$. However, although it has high modulus, it is a fragile and brittle material, with a low elongation at break similarly to polystyrene ${ }^{[10]}$.

To adequate PLA properties for packaging application and to improve its thermal and mechanical properties, particularly its flexural properties, this polymer is usually modified by copolymerization with other monomers or by plasticization $^{[5,10-13]}$.

Plasticization usually improves the processability of polymers, as well as increase the polymer flexibility and ductility in amorphous polymers. The efficiency is in general evaluated in terms of the decreasing in the glass transition temperature $\left(\mathrm{T}_{\mathrm{g}}\right)$ and increasing of toughness, and it is dependent on polymer molar mass and amount of plasticizer ${ }^{[13]}$.

The solubility parameter and the magnitude of polymer-plasticizing interaction are usually used to evaluate the miscibility between the material components and are good elements to facilitate the selection of an effective plasticizer. Thus, plasticizers are important non-volatile molecules which actuate modifying the intermolecular interactions between the polymer chains by preferential interactions with the macromolecular chains. These interactions change chain conformation, resulting in increasing of molecular mobility ${ }^{[10]}$.

Aiming to investigate the efficiency of oligoester as PLA biodegradable plasticizers, a oligoester based on two 
bio-based monomers, sebacic acid and trimethylene glycol was synthesized and added to a commercial PLA. So, in this paper the crystallization, thermal and mechanical behavior of these oligoester plasticized-PLA are reported.

\section{Materials and Methods}

\subsection{Materials}

PLA Ingeo 4043D $\left(M_{n}=160.000 \mathrm{~g} / \mathrm{mol}\right)$ film grade from NatureWorks LLC was used as received. Chloroform 99.8\% (amilene stabilized) was furnished by Tedia Brazil. Dimethylsebacate and trimethylenediol (propan-1,3-diol) Aldrich and zinc acetate from Spectrum were used as received.

\subsection{Synthesis of oligosebacate}

The synthesis of the oligo(trimethylene sebacate) (OTS) was carried out by a bulk polycondensation of dimethylsebacate and trimethylenediol using zinc acetate as catalyst. The reaction took place in a single stage by using equimolar proportion of the monomers according to procedure previously described in the literature ${ }^{[14]}$. Thus, the monomers and catalyst $(0.5 \mathrm{wt} . \%)$ were placed in a glass flask and heated to $200{ }^{\circ} \mathrm{C}$. By using vacuum, methanol was progressively removed during $2 \mathrm{~h}$. At the end of this time, the molten oligoester was poured into a glass surface to solidify.

\subsection{Oligoester characterization}

The oligoester was analyzed by FTIR in a Varian Excalibur 3100 FT-IR by Attenuated Total Reflectance (ATR) in the range of 4000-400 $\mathrm{cm}^{-1} .{ }^{1} \mathrm{H}$ NMR spectrum of OTS was obtained in a Varian NRM equipment model Mercury VX-300, using $\mathrm{CDCl}_{3}$ as solvent. The molecular weight was determined by GPC using a Shimadzu LC equipment with refractive index detector, chloroform as solvent and monodisperse polystyrene as calibration standard. The analyses were carried out in a flow rate of $1.0 \mathrm{~mL} / \mathrm{min}$, injection volume of $20 \mu \mathrm{m}$, at $25^{\circ} \mathrm{C}$. The number and weight average molar mass $\left(\mathrm{M}_{\mathrm{n}}\right.$ and $\mathrm{M}_{\mathrm{w}}$, respectively) and polydispersity $\left(M_{w} / M_{n}\right)$ were determined by a Shimadzu software. Thermal transition temperatures were determined in a DSC Hitachi model 7020 in the temperature range from -80 to $100{ }^{\circ} \mathrm{C}$ at $10{ }^{\circ} \mathrm{C} / \mathrm{min}$. Samples were first heated, followed by a fast cooling (quenching) at $50{ }^{\circ} \mathrm{C} / \mathrm{min}$ up to $-80{ }^{\circ} \mathrm{C}$ and subsequently reheated at $10{ }^{\circ} \mathrm{C} / \mathrm{min}$.

\subsection{Preparation of PLA films}

PLA films were prepared by casting from $10 \mathrm{wt} . / \mathrm{v} \%$ chloroform solutions. OTS was added to these solutions to attain the final concentration of 1,5 and $10 \mathrm{wt} . \%$ in relation to PLA. The solutions containing PLA and OTS were casted over to $289 \mathrm{~cm}^{2}$ mold with $3 \mathrm{~mm}$ thickness and dried for
7 days. After this time, the films were dried under vacuum for more $24 \mathrm{~h}$ as attempt to eliminate the residual solvent.

\subsection{Characterization of plasticized films}

PLA films were analyzed by TA DSC equipment under nitrogen atmosphere in the temperature range from 25 to $200^{\circ} \mathrm{C}$ at $10^{\circ} \mathrm{C} / \mathrm{min}$. Three heating runs were used to evaluate the polymer thermal transitions. The degree of crystallinity was calculated using the standard melting enthalpy reported by Sarasua et al. ${ }^{[15]}(106 \mathrm{~J} / \mathrm{g})$, considering the enthalpy of crystallization on heating and OTS weight fraction. Thermal stability was analyzed in a TA Thermoanalyser Q500 from 25 to $700{ }^{\circ} \mathrm{C}$ at $10{ }^{\circ} \mathrm{C} / \mathrm{min}$ under nitrogen flow. X-ray diffraction were carried out in a diffractometer Rigaku Miniflex model using $\mathrm{CuK} \alpha$ radiation (wavelength, $1.5418 \AA$ ) in the $2 \theta$ range $2^{\circ}$ to $50^{\circ}, 0.05^{\circ} \mathrm{step} / \mathrm{s}$ at room temperature. Rheological behavior of films containing $10 \mathrm{wt} . \%$ OTS was studied using a TAAR 2000 rheometer in the parallel plate geometry (diameter $25 \mathrm{~mm}$ ) at $165^{\circ} \mathrm{C}$. Disc-like specimens with $2 \mathrm{~cm}$ diameter were used. Tests were carried out in the $10^{-1}-10^{2} \mathrm{~Hz}$ interval at $5 \%$ deformation to have the material response in the linear viscoelastic regime. DMA analysis were carried out in a TA DMA Q800 model, from -20 to $120^{\circ} \mathrm{C}$ at $1 \mathrm{~Hz}$ frequency and heating rate of $3{ }^{\circ} \mathrm{C} / \mathrm{min}$. Rectangular specimens with $13.0 \times 7.0 \times 0.15 \mathrm{~mm}$ were used and experiments were done in the tensile mode with a controlled force of $0.01 \mathrm{~N}$. Films tensile tests were carried out in a EMIC DL-300 universal machine at $5 \mathrm{~mm} / \mathrm{min}$ after conditioning the specimens at $23^{\circ} \mathrm{C}$ for $48 \mathrm{~h}$. Specimens were prepared according the ASTM D882-12 method for films.

\section{Results and Discussions}

\subsection{Oligosebacate synthesis and characterization}

The oligo(trimethylene sebacate) (OTS) was obtained by polycondensation of dimethylsebacate and propan-1,3-diol catalyzed by zinc acetate (Figure 1). The OTS presented white color and a wax-like aspect. FTIR was used to confirm its structure (Figure 2). From the figure, it is possible to observe the carbonyl characteristic absorption bands at $1727 \mathrm{~cm}^{-1}$ $(\mathrm{C}=\mathrm{O})$ and $1177 \mathrm{~cm}^{-1}(\mathrm{C}-\mathrm{C}(\mathrm{C}=\mathrm{O})-\mathrm{O})$. The spectrum shows also absorption bands at 2926 and $2853 \mathrm{~cm}^{-1}$ attributed to asymmetric and symmetric methylene groups in the oligoester structure as well as bands at $1350-1150 \mathrm{~cm}^{-1}$ region characteristic of vibration of long chain esters. The spectrum presents a band at $3500 \mathrm{~cm}^{-1}$ attributed to $\mathrm{O}-\mathrm{H}$ bonds of alcohols, related to the hydroxyl end groups ${ }^{[16]}$.

GPC results revealed that the OTS has $M_{n}=2,920 \mathrm{~g} / \mathrm{mol}$, $M_{w}=6,120 \mathrm{~g} / \mathrm{mol}$ and polydispersity $\mathrm{M}_{\mathrm{w}} / \mathrm{M}_{\mathrm{n}}=2.1$. From a second DSC heating run, the oligomer showed a $\mathrm{T}_{\mathrm{g}}$ at $-22^{\circ} \mathrm{C}$ and cold crystallization $\left(\mathrm{T}_{\mathrm{cc}}\right)$ at $35^{\circ} \mathrm{C}\left(\Delta \mathrm{H}_{\mathrm{cc}}=0.43 \mathrm{~J} / \mathrm{g}\right)$ with a melting transition $\left(\mathrm{T}_{\mathrm{m}}\right)$ at $50{ }^{\circ} \mathrm{C}$, indicating that it is a semi-crystalline material. On cooling, the OTS shows a<smiles>C=CC(C)(C)OCCCOC(=O)CC(=O)OCCCOC(C)(C)C</smiles>

Figure 1. Reaction of transesterification to obtain oligo(trimethylene sebacate). 


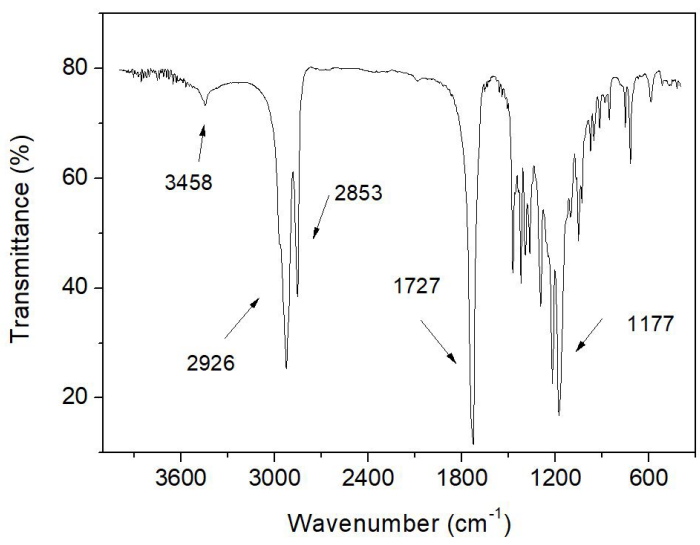

Figure 2. FTIR spectrum of OTS.

crystallization temperature $\left(\mathrm{T}_{\mathrm{c}}\right)$ at around $27^{\circ} \mathrm{C}\left(\Delta \mathrm{H}_{\mathrm{c}}=4 \mathrm{~J} / \mathrm{g}\right)$. In the literature, the reported sebacate polyester with structure closest to OTS is the poly(ethylene sebacate) with $\mathrm{M}_{\mathrm{w}}=10,000 \mathrm{~g} / \mathrm{mol}$ that presented $\mathrm{T}_{\mathrm{g}}=-30{ }^{\circ} \mathrm{C} \mathrm{T}_{\mathrm{m}}=74^{\circ} \mathrm{C}^{[14]}$.

The thermal stability of OTS was evaluated by thermogravimetry. The OTS showed a bimodal weight loss DTG profile, with a first maximum degradation rate $\mathrm{T}_{\max }=399^{\circ} \mathrm{C}\left(\mathrm{T}_{\text {ONSET }}=336{ }^{\circ} \mathrm{C}\right)$, followed by a second small weight loss at high temperature $\left(\mathrm{T}_{\max }=440{ }^{\circ} \mathrm{C}\right)$. The stability of OTS was superior to that observed for the PLA used in this work.

\subsection{Plasticized films of PLA}

Films of PLA containing OTS was analyzed by different physical methods to have insight on the influence of this additive on the main PLA properties and evaluate the plasticizing action of this oligomer.

\subsubsection{Thermal transitions and crystallinity}

Main transitions of PLA and PLA/OTS films were identified by DSC. Table 1 resumes the values of melting transition temperature $\left(\mathrm{T}_{\mathrm{m}}\right)$ and degree of crystallinity $\left(X_{\mathrm{c}}\right)$ obtained in the first heating run of DSC analyses which aims to evaluate the crystallization process during film formation by polymer solution evaporation. It is possible to observe that although the PLA casting film presented low crystallinity $\left(X_{c}=6 \%\right.$ ), PLA/OTS films showed $X_{c}$ significantly higher than this PLA film ( $X_{c}$ from 33 to $37 \%$ ). It is also shown that $X_{c}$ increased slightly as OTS content increased. The degree of crystallinity of PLA/OTS films was even higher than that observed for PLA pellets. This higher crystallinity may be attributed to the presence of the oligoester which induces the polymer crystallization during solvent evaporation by increasing the mobility of polymer chain ${ }^{[17]}$.

Figure 3 presents the curves related to a $3^{\text {rd }}$ heating run of PLA films obtained after a controlled cooling at $10^{\circ} \mathrm{C} / \mathrm{min}$ from the melt. From these curves, it is possible to see that the $\mathrm{T}_{\mathrm{m}}$ for PLA and PLA/OTS films is superior as compared to that of PLA pellets, which may be attributed to the increase of crystal perfection due to solvent interaction with polymer chains during film formation ${ }^{[17]}$.

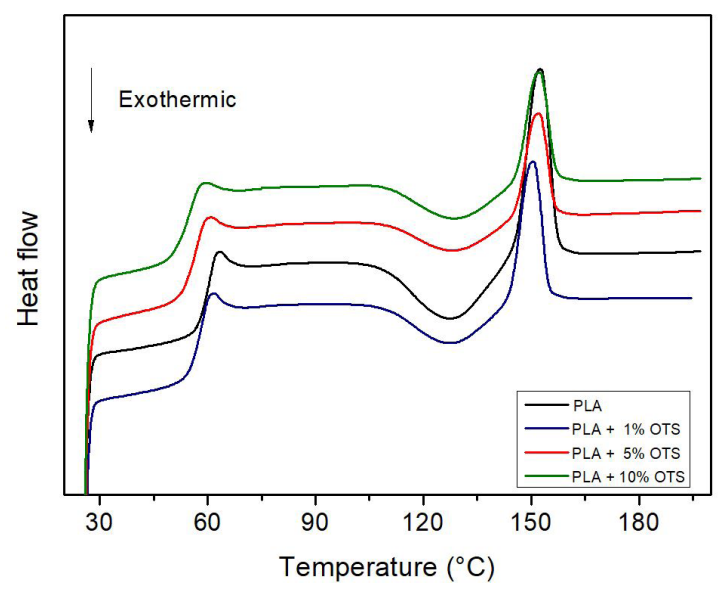

Figure 3. DSC curves ( $3^{\text {rd }}$ heating run) of PLA and PLA/OTS films.

Table 1. Main thermal transitions and degree of crystallinity of PLA and PLA/OTS casting films obtained by Differential Scanning Calorimety (DSC).

\begin{tabular}{lcccccc}
\hline Material & $\begin{array}{c}\text { OTS } \\
(\mathbf{\%})\end{array}$ & $\begin{array}{c}\mathbf{T}_{\mathbf{m}}{ }^{\mathbf{a}} \\
\left({ }^{\circ} \mathbf{C}\right)\end{array}$ & $\begin{array}{c}X_{\mathbf{c}}{ }^{\mathbf{a}} \\
(\mathbf{\%})\end{array}$ & $\begin{array}{c}\mathbf{T}^{\mathbf{b}} \\
\left({ }^{\mathbf{b}} \mathbf{C}\right)\end{array}$ & $\begin{array}{c}\mathbf{T}_{\mathbf{m}}{ }^{\mathbf{}} \\
\left({ }^{\circ} \mathbf{C}\right)\end{array}$ & $\begin{array}{c}\mathbf{T}_{\mathbf{c c}}{ }^{\mathbf{c}} \\
\left({ }^{\circ} \mathbf{C}\right)\end{array}$ \\
\hline PLA & 0 & 149 & 22 & 58 & 149 & 124 \\
Pellets & & & & & & \\
PLA(film) & 0 & 152 & 6 & 60 & 152 & 127 \\
PLA/OTS & 1 & 151 & 33 & 57 & 152 & 129 \\
& 5 & 153 & 34 & 55 & 152 & 128 \\
& 10 & 150 & 37 & 53 & 152 & 128 \\
\hline
\end{tabular}

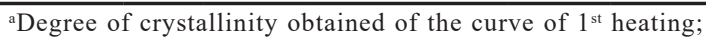
${ }^{\mathrm{b}} \mathrm{T}_{\mathrm{g}}$ obtained of the curve of $2^{\text {nd }}$ heating; ${ }^{\mathrm{c}}$ Transitions values obtained of the curve of the $3^{\text {rd }}$ heating.

It is possible to note that the curves of all PLA casting films obtained from the $3^{\text {rd }}$ heating run showed the same profile with a glass transition, a cold crystallization and a melting transition. It is important to mention also that all curves presented a similar cold crystallization $\left(\mathrm{T}_{c c}\right)$ and melting transition $\left(\mathrm{T}_{\mathrm{m}}\right)$ temperatures, i.e., $\mathrm{T}_{\mathrm{m}}$ and $\mathrm{T}_{\mathrm{cc}}$ remain practically constant as OTS content increased. It must be also mentioned that during the cooling at $10^{\circ} \mathrm{C} /$ min employed before the $3^{\text {rd }}$ heating, no crystallization peak was observed for these samples. However, the influence of the oligomer in the crystallization process can be supported by the $X_{\mathrm{c}}$ values observed in the first heating run that are higher than those from the third heating. This difference in $X_{\mathrm{c}}$ is related to the fact that the casting films were prepared and dried at room temperature. Thus, the films were crystallized slowly during solvent evaporation. So, in the first heating, $X_{\mathrm{c}}$ is higher while in the $3^{\text {rd }}$ heating after a cooling at $10^{\circ} \mathrm{C} / \mathrm{min}$ it is lower, since at this cooling rate the time is not enough for adequate material crystallization ${ }^{[18]}$.

Addition of OTS to PLA decreased the $\mathrm{T}_{\mathrm{g}}$ and this decrease is enhanced as the concentration increased, indicating the plasticizing effect of the oligomer.

Figure 4 shows the behavior of $\mathrm{T}_{\mathrm{g}}$ obtained experimentally and $\mathrm{T}_{\mathrm{g}}$ predicted according the Fox Equation (Equation 1) ) $^{[19]}$ for PLA/OTS films containing 1, 5 and $10 \mathrm{wt} . \%$ of OTS. 


$$
1 / T_{g}=W_{x} /\left(T_{g} x\right)+W_{y} /\left(T_{g} y\right)
$$

In this equation that is used to evaluate the miscibility of polymer blends ${ }^{[20]}, W \mathrm{x}$ e $W \mathrm{y}$ are the molar fraction and $T_{G} \mathrm{x}$ e $T_{G} \mathrm{y}$ are the glass transition temperatures of each blend components. It is possible to observe that the results presented a linear behavior, with a line coming from the same point, since in the $1 \mathrm{wt} . \%$ PLA/OTS system, values of theoretical and experimental $\mathrm{T}$ are practically the same. As OTS concentration increases, $\mathrm{T}_{\mathrm{g}}$ values start to become far from each other. This result suggests a partial miscibility of OTS in PLA, since although it is clear the influence of the oligomer on the glass transition process by the reduction of the $\mathrm{T}_{\mathrm{g}}$ of PLA, with increasing content of OTS, the theoretical values of $\mathrm{T}_{\mathrm{g}}$ are not attained as expected for a completely miscible system.

\subsubsection{Thermal stability}

Commercial PLA (pellets) presented a unique stage of weight loss with $\mathrm{T}_{\text {ONSET }}$ and $\mathrm{T}_{\max }$ of 336 and $358{ }^{\circ} \mathrm{C}$, respectively. However, in the PLA films prepared by casting from chloroform solutions two stages of weight loss are noted: one with $\mathrm{T}_{\text {ONSET }} \mathrm{e}_{\text {max }}$ around the same temperatures observed for PLA pellets, and another at lower temperatures $\left(\mathrm{T}_{\text {ONSET }}=85^{\circ} \mathrm{C}\right.$ and $\left.\mathrm{T}_{\max }=102^{\circ} \mathrm{C}\right)$. This first stage of weight loss is attributed to the presence of residual solvent in the films ${ }^{[21]}$, due the know strong interaction between chlorine and carbonyl groups ${ }^{[22]}$. This interaction also explains why this temperature of weight loss attributed to the residual

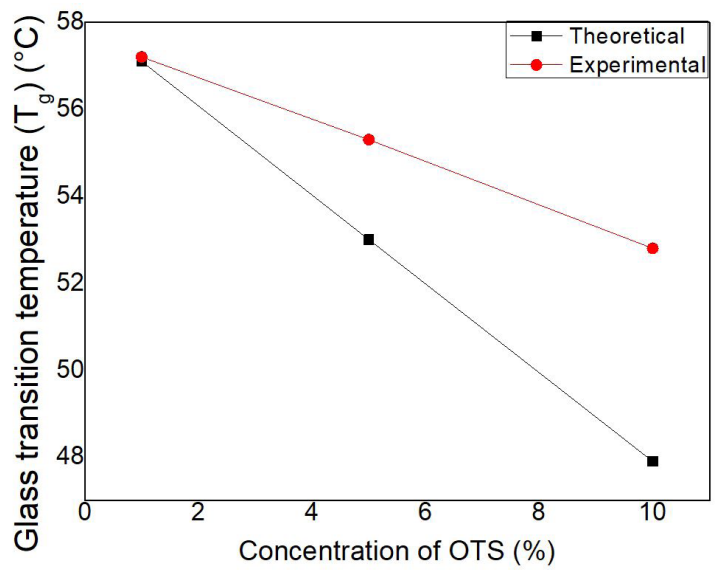

Figure 4. OTS concentration versus theoretical and experimental glass transition temperature. solvent $\left(85^{\circ} \mathrm{C}\right)$ is superior to the boiling point of chloroform $\left(60{ }^{\circ} \mathrm{C}\right)$. To prove this fact, the thermal stability of PLA films was compared with that of PLA extruded. The results presented in Table 2 support that this first stage of weight loss is due to residual solvent which is still present in the films even after vacuum treatment for $24 \mathrm{~h}$.

Processing in the molten state can cause chain break and decrease in the molecular weight, influencing the results of thermal decomposition shown by TG analyses. In this work, films were prepared by casting, process that did not cause any molecular weight reduction. Thus, the different weight loss profiles observed and final amount of residues at $700^{\circ} \mathrm{C}$ are due to the presence and content of the oligoplasticizer in the material. All the films showed two stages of weight loss, the first around $100^{\circ} \mathrm{C}$ and the second at about $350{ }^{\circ} \mathrm{C}$. For PLA pellet, only one stage was observed differently of the cast films, confirming that the first stage of weight loss is due to solvent loss. This weight loss is in the range of 7-11 wt.\%, what indicate that a considerable amount of solvent remains in the polymer even after $24 \mathrm{~h}$ of vacuum treatment at room temperature. These films were not dried at more severe condition by heating to avoid annealing of the films, what would influence their crystallinity.

Considering the second stage of weight loss, a decrease in $\mathrm{T}_{\text {ONSET }}$ and $\mathrm{T}_{\max }$ takes place when the plasticizer is added to PLA. This decrease is easily seen when the $T_{\max }$ of the non-additivated film is compared with the $\mathrm{T}_{\text {max }}$ of the sample containing $10 \mathrm{wt} \%$ of OTS. It is important to emphasize that the $\mathrm{T}_{\text {onset }}$ of the non-additivated film is higher than those shown for PLA/OTS films. This fact can be explained considering the influence of the oligoester soluble fraction in the polymer which must be homogeneous dispersed in the PLA matrix ${ }^{[12]}$.

The OTS used in this work has $\mathrm{T}_{\text {max }}=400{ }^{\circ} \mathrm{C}$, which is relatively close to PLA film $\left(\mathrm{T}_{\max }=354.2^{\circ} \mathrm{C}\right)$. This means that the DTG peak of the second decomposition stage is not only related to PLA, but also to OTS main degradation. Thus, it is possible to conclude that addition of OTS promotes a small reduction of thermal stability of the material.

\subsubsection{Morphology by X-ray diffraction}

X-ray diffraction (XRD) was used to evaluate the influence of the oligoester on the crystallinity of the films. Figure 5 shows the XRD curves of PLA and PLA/OTS films containing 1, 5 and $10 \mathrm{wt} \%$ OST. The XRD curve of the PLA film showed an amorphous halo, indicating low degree of crystallinity of this film. However, PLA/OTS films presented three crystalline reflections at 17, 19 and

Table 2. Evaluation of weight loss stages for PLA pellet, PLA extruded and PLA cast films.

\begin{tabular}{|c|c|c|c|c|c|c|c|}
\hline \multirow[b]{2}{*}{ PLA Sample } & \multirow{2}{*}{$\begin{array}{l}\text { OTS } \\
(\%)\end{array}$} & \multicolumn{3}{|c|}{ Stage I } & \multicolumn{3}{|c|}{ Stage II } \\
\hline & & $\begin{array}{c}\mathbf{T}_{\text {ONSET }} \\
\left({ }^{\circ} \mathbf{C}\right)\end{array}$ & $\begin{array}{l}T_{\max } \\
\left({ }^{\circ} \mathrm{C}\right)\end{array}$ & Weigh loss (\%) & $\begin{array}{c}\mathbf{T}_{\text {ONSET }} \\
\left({ }^{\circ} \mathbf{C}\right)\end{array}$ & $\begin{array}{l}T_{\max } \\
\left({ }^{\circ} \mathrm{C}\right)\end{array}$ & $\begin{array}{c}\text { Residue at } 700 \\
{ }^{\circ} \mathrm{C}(\%)\end{array}$ \\
\hline Pellet & 0 & - & - & - & 336 & 358 & 0.9 \\
\hline Extruded & 0 & - & - & - & 329 & 353 & 1.8 \\
\hline Film & 0 & 85 & 102 & 7.8 & 332 & 354 & 0.4 \\
\hline \multirow[t]{3}{*}{ PLA/OTS } & 1 & 87 & 120 & 8.4 & 329 & 355 & 0.3 \\
\hline & 5 & 89 & 125 & 7.9 & 324 & 356 & 0.7 \\
\hline & 10 & 96 & 125 & 6.6 & 329 & 342 & 1.2 \\
\hline
\end{tabular}




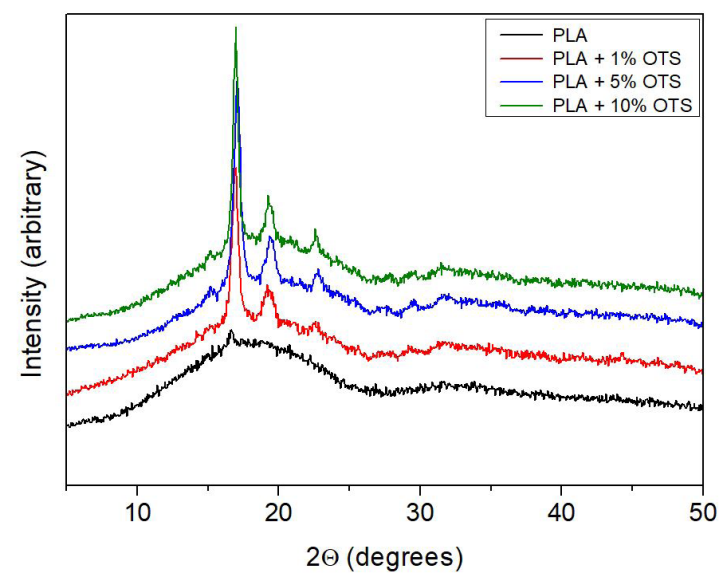

Figure 5. X ray diffraction curves of PLA and PLA/OTS films.

$23^{\circ}$ indicating that these films are semi-crystalline materials. According to Byun et al. ${ }^{[17]}$, these reflections are characteristics of PLA casting films from chloroform. It is interesting to note that the intensity of the reflection at $23^{\circ}$ increases linearly as OST content increases. This indicates that OTS seems to be inducing PLA crystallization. According to DSC data, OTS is only partially soluble in PLA at higher contents. No crystalline peak that could be attributed to OTS crystallization was observed. So, this increase in crystallinity seems to be related a nucleation effect of OTS insoluble phase that is probably in the amorphous state.

\subsubsection{Rheological behavior}

Storage modulus (G'), loss modulus (G') and complex viscosity $\left(\eta^{*}\right)$ as a function of frequency of PLA/OTS was evaluated at $165^{\circ} \mathrm{C}$ to investigate the rheological behavior of these materials (Figures 6 and 7). The measurements were carried out at deformation of $5 \%$, which is in the interval of linear viscoelasticity of high molecular weight of PLA without any additive ${ }^{[23,24]}$.

Figure 6 shows the G' and G' versus frequency curves for the PLA and PLA/OTS containing $10 \mathrm{wt} . \%$ of the oligomer. From the figure, one can observe that G' decreased with addition of the oligoester as expected, being this effect practically the same along the region of low and high frequencies. The behavior of loss modulus G" versus frequency shows also a reduction of G" with the addition of the oligomer. In this case, the decrease of G' is more pronounced in frequencies lower than $10 \mathrm{~Hz}$. The figure shows a transition from a fluid-like (G" $\left.>G^{\prime}\right)$ to a solid-like (G'> G') between 5 and $20 \mathrm{~Hz}$. The crossover frequency shifts to a higher value with the addition of OTS, indicating that the response becomes more fluid-like, as should be expected.

Figure 7 shows the curves of complex viscosity $\left(\eta^{*}\right)$ versus frequency for these two samples. Also for this rheological property, non-additivated PLA presents a higher value compared with the sample containing $10 \mathrm{wt} . \%$ OTS. This expected decrease in $\eta *$ is due to oligoester molecules solubilization in the PLA matrix which reduces the melt

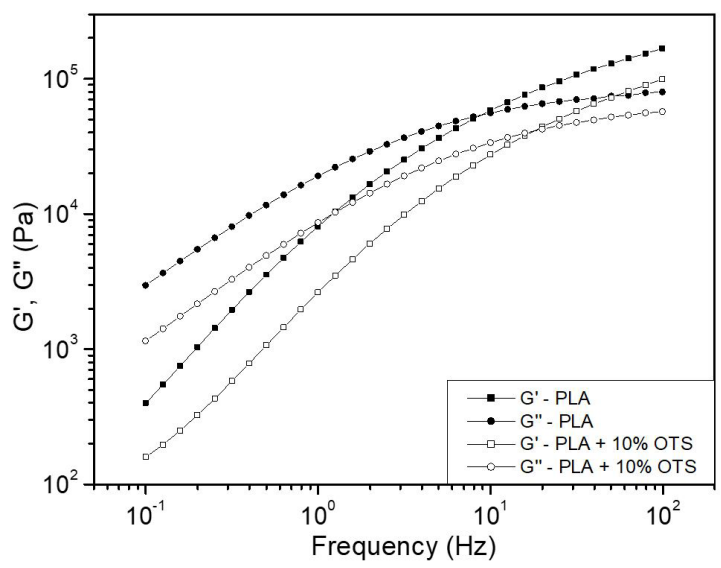

Figure 6. Storage modulus (G') and loss modulus (G') as a function of the frequency for PLA and PLA/OTS film containing 10 wt.\% OTS.

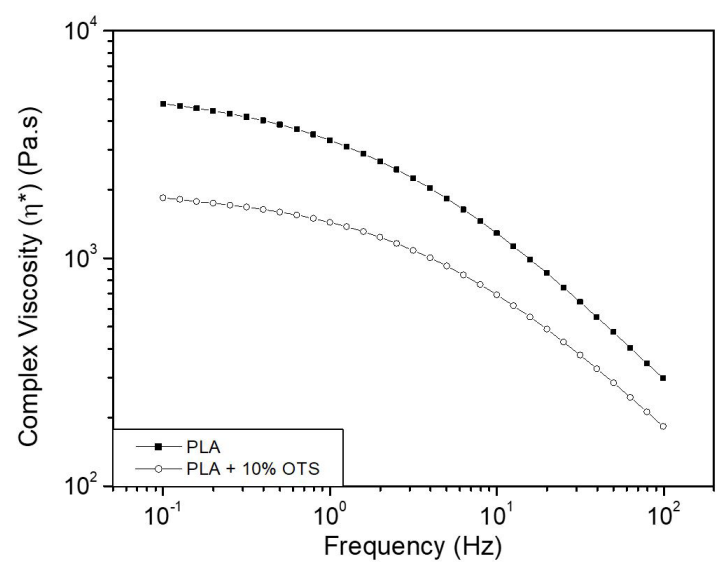

Figure 7. Complex viscosity as function of frequency for PLA and PLA/OTS film containing $10 \mathrm{wt} \%$ OTS.

viscosity $^{[25]}$. This behavior is another indication of the plasticization effect of OTS over PLA during the processing.

\subsubsection{Dynamic mechanical behavior}

Curves of storage modulus (E') of PLA and PLA/OTS films obtained from dynamic mechanical analysis are presented in Figure 8. The curves show a typical behavior of thermoplastic polymers, with a drastic decay of E' when approaching to PLA glass transition. After $\mathrm{T}_{\mathrm{g}}$, a plato can be identified. According to Huda et al. ${ }^{[26]}$, this behavior observed for PLA casting films like elastomers, which presents amorphous and crystalline phases in their structure. From the curves, it is possible to note that the modulus decreases when the content of OTS is increased in the films.

Values of storage modulus for these films in temperatures which are representatives for application condition, i.e. below and above $\mathrm{T}_{\mathrm{g}}\left(-20,0\right.$ and $\left.60^{\circ} \mathrm{C}\right)$, were selected and are presented in Table 3. From the table, by analyzing each temperature separately, it is possible to observe that a significant decrease in the storage modulus occurred at 
-20 and $0{ }^{\circ} \mathrm{C}$ as the concentration of the oligomer increases. For $60^{\circ} \mathrm{C}$, close to the glass transition temperature, a drastic reduction in the $\mathrm{E}^{\prime}$ took place. This behavior is expected since at $\mathrm{T}$ the system acquires high level of chain segmental mobility ${ }^{[26]}$. After $70{ }^{\circ} \mathrm{C}$, an increase of E'is observed for PLA and PLA/OTS containing 1 wt.\% OTS that can be attributed to thermal crystallization, meaning that these films had still amorphous materials capable of crystallizing.

Figure 9 presents the loss modulus (E") curves as a function of temperature for PLA and PLA/OTS with 1, 5 e 10 wt.\% OTS, respectively. The curves presented the characteristic peak of relaxation phenomenon related to the glass-rubber transition. Values of $\mathrm{T}_{\mathrm{g}}$ were obtained from the maximum of loss modulus peaks (Table 3 ). It is possible to observe that the $\mathrm{T}_{\mathrm{g}}$ values obtained from the lost modulus peaks are lower than those observed from DSC (Table 1). This difference can be related to the cyclic mechanical stress applied in tensile mode in addition to DMA heating, differently from DSC, which uses only thermal heating. The intensity of these maximum peaks for casting films is related with the relaxation index inhibited by the crystalline phase of the films ${ }^{[26]}$. Thus, it is possible to observe the less intense peak for PLA/OTS $10 \mathrm{wt} . \%$ that has higher degree of crystallinity according to DSC results. The thermal crystallization of PLA and PLA/OTS with 1 wt.\% OTS was also detected by the loss modulus curves.

Although, it was observed a certain degree of haze in the films with higher content of OTS, no indication of the OTS phase separation could be detected from dynamic mechanical tests.

\subsubsection{Tensile properties}

Tensile properties of PLA films containing OTS were evaluated according the ASTM D 882-12 method. Table 4 resumes the results of stress and strain at yield and at break for films with 1, 5 and $10 \mathrm{wt} \% \%$ of OTS.

According to literature ${ }^{[27]}$, the young's modulus should decrease with addition of the oligomer, since plasticizers reduce the intermolecular forces that actuate in the macromolecular chains, increasing material flexibility. Although, a considerable experimental error was observed in the elastic modulus values (not presented in the table), the film containing $1 \mathrm{wt} . \%$ OTS showed a slightly increase of modulus. For the films with 5 and $10 \mathrm{wt} \%$ OTS, the expected decrease in the elastic modulus was observed.

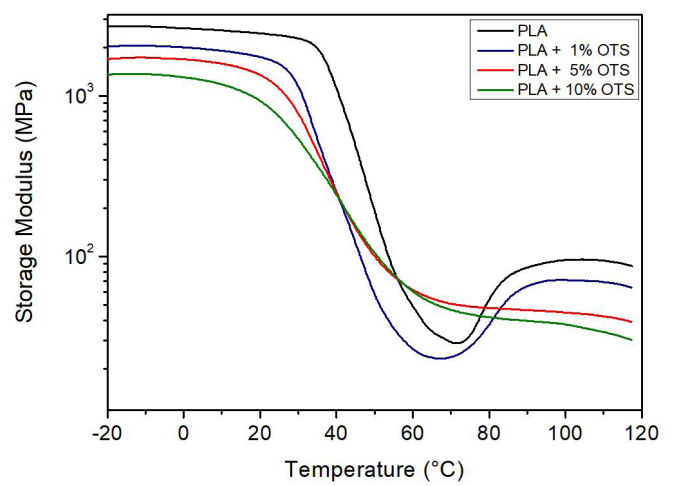

Figure 8. Storage modulus versus temperature for PLA and PLA/OTS films.

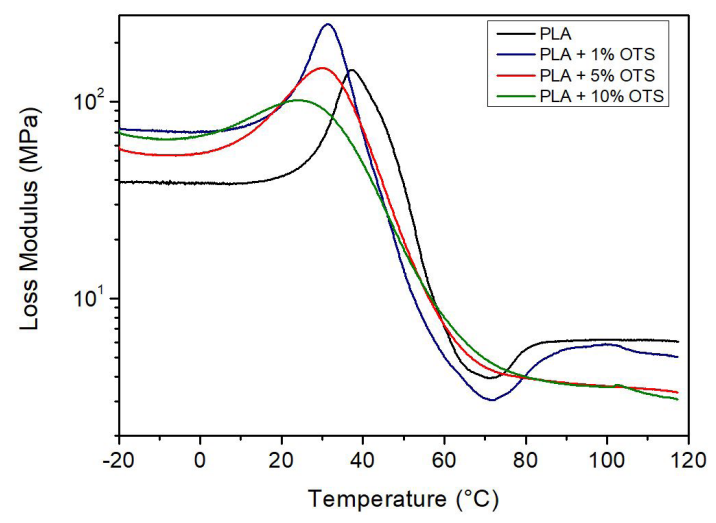

Figure 9. Loss modulus curves for PLA e PLA/OTS films.

Table 3. Storage modulus at $-20,0$ and $60^{\circ} \mathrm{C}$ and $\mathrm{T}_{\mathrm{g}}$ obtained from loss modulus peak of PLA and PLA/OTS casting films.

\begin{tabular}{|c|c|c|c|c|c|}
\hline \multirow{2}{*}{$\begin{array}{c}\text { Sample } \\
\text { (casting film) }\end{array}$} & \multicolumn{4}{|c|}{$\mathbf{E}^{\prime}(\mathbf{M P a})$} & \multirow{2}{*}{$\begin{array}{c}\mathrm{T}_{\mathrm{g}} \\
\left({ }^{\circ} \mathrm{C}\right)^{\mathrm{a}}\end{array}$} \\
\hline & OTS (wt.\%) & $-20^{\circ} \mathrm{C}$ & $\mathbf{0}^{\circ} \mathrm{C}$ & $60^{\circ} \mathrm{C}$ & \\
\hline \multirow[t]{4}{*}{ PLA/OTS } & 0 & 2711 & 2639 & 49 & 37 \\
\hline & 1 & 2005 & 2007 & 27 & 32 \\
\hline & 5 & 1661 & 1693 & 63 & 31 \\
\hline & 10 & 1337 & 1306 & 61 & 25 \\
\hline
\end{tabular}

aValues obtained from peak maximum of E'.

Table 4. Tensile properties of PLA and PLA/OTS films obtained by casting.

\begin{tabular}{ccccc}
\hline Sample & $\begin{array}{c}\text { OTS } \\
(\mathbf{w t} \%)\end{array}$ & $\begin{array}{c}\text { Maximum Stress } \\
(\mathbf{M P a})\end{array}$ & $\begin{array}{c}\text { Deformation at } \\
\text { maximum stress } \\
(\%)\end{array}$ & $\begin{array}{c}\text { Ultimate stress } \\
(\mathbf{M P a})\end{array}$ \\
\hline PLA & 0 & $26 \pm 8$ & $6 \pm 0$ & $14 \pm 5$ \\
PLA/OTS & 1 & $25 \pm 2$ & $6 \pm 0$ & $9 \pm 3$ \\
& 5 & $22 \pm 3$ & $298 \pm 11$ & $-16 \pm 2$ \\
& 10 & $16 \pm 2$ & $261 \pm 41$ & $21 \pm 4$ \\
\hline
\end{tabular}




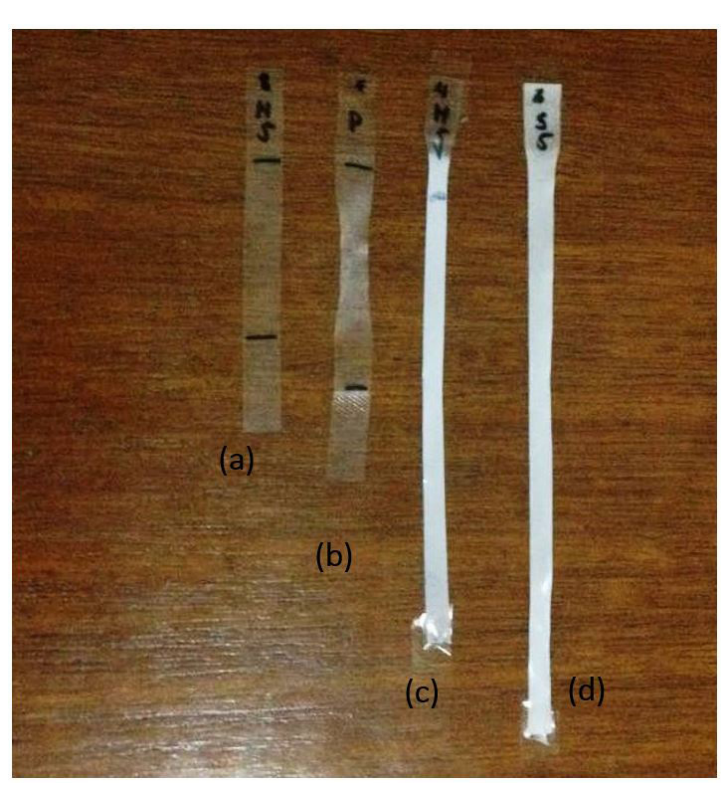

Figure 10. Tensile test specimens of (a) PLA before tensile test and after the test: (b) PLA, (c) PLA/ 5 wt.\% OMT (d) PLA/ 10 wt.\% OTS.

Addition of OTS to PLA films produced the expected effect of increasing the elongation at break and consequently the ductility of these films (Figure 10). The observed values of elongation at break of PLA/OTS films with 5 and $10 \mathrm{wt} . \%$ indicates a marked increase in the ductility of the films, which corroborate the plasticizing effect of OTS ${ }^{[27]}$.

\section{Conclusions}

A oligoester based on the bio-based monomers trimethylene glycol and sebacic acid (OTS) was synthesized and applied to PLA plasticization. According to thermal analyses studies, it was possible to demonstrate that the addition of this oligomer to the polyester decreases the glass transition temperature of the films, evidencing that OTS acts canceling polymer-polymer interaction which allows to increase mobility of the amorphous phase. Nevertheless, a partial miscibility which decrease transparency was confirmed by the comparison of the expected theoretical and experimental $\mathrm{T}_{\mathrm{g}}$ values. The oligomer also produced an unexpected increase of the degree of crystallinity of PLA films, contributing also for the decrease in their transparency. PLA films containing OTS show lower storage moduli that decreased as the content of OTS increased. From mechanical tests, these PLA-OTS films presented an increase in the elongation at break, suggesting increase in the ductility. By considering the results, it is evident the plasticizing effect of this oligomer on PLA.

\section{Acknowledgements}

The authors are grateful to Conselho Nacional de Pesquisa Científica e Tecnológica - CNPq (Process 310917/2014-0) and FAPERJ (E-26/201.304/2014) for financial support and CAPES for the E.M. Inacio scholarship.

\section{References}

1. Siracusa, V., Rocculi, P., Romani, S., \& Rosa, M. D. (2008). Biodegradable polymers for food packaging: a review. Trends in Food Science \& Technology, 19(12), 634-643. http://dx.doi. org/10.1016/j.tifs.2008.07.003.

2. González, A., \& Alvarez Igarzabal, C. I. (2013). Soy protein: poly(lactic acid) bilayer films as biodegradable material for active food packaging. Food Hydrocolloids, 33(2), 289-296. http://dx.doi.org/10.1016/j.foodhyd.2013.03.010.

3. Rosa, D. S., Filho, R. P., Chui, Q. S. H., Calil, M. R., \& Guedes, C. G. F. (2003). The biodegradation of poly-b(hydroxybutyrate), poly-b-(hydroxybutyrate-co-b-valerate) and poly(e-caprolactone) in compost derived from municipal solid waste. European Polymer Journal, 39(2), 233-237. http:// dx.doi.org/10.1016/S0014-3057(02)00215-X.

4. Suresh Kumar, M., Mudliar, S. N., Reddy, K. M., \& Chakrabarti, T. (2004). Production of biodegradable plastics from activated sludge generated from a food processing industrial wastewater treatment plant. Bioresource Technology, 95(3), 327-330. http:// dx.doi.org/10.1016/j.biortech.2004.02.019. PMid:15288276.

5. Arrieta, M. P., López, J., Hernández, A., \& Rayón, E. (2014). Ternary PLA-PHB-Limoneno blends intended for biodegradable food packaging applications. European Polymer Journal, 50, 255-270. http://dx.doi.org/10.1016/j.eurpolymj.2013.11.009.

6. Rosa, D. S., Lotto, N. T., Lopes, D. R., \& Guedes, C. G. F. (2004). The use of roughness for evaluating the biodegradation of poly- $\beta$-(hydroxybutyrate) and poly- $\beta$-(hydroxybutyrateco- $\beta$-valerate). Polymer Testing, 23(1), 3-8. http://dx.doi. org/10.1016/S0142-9418(03)00042-4.

7. Ljungberg, N., Colombini, D., \& Wesslén, B. (2005). Plasticization of poly(lactic acid) with oligomeric malonate esteramides: dynamic mechanical and thermal film properties. Journal of Applied Polymer Science, 96(4), 992-1002. http:// dx.doi.org/10.1002/app.21163.

8. Martin, O., \& Avérous, L. (2001). Poly(lactic acid): plasticization and properties of biodegradable multiphase systems. Polymer, 42(14), 6209-6219. http://dx.doi.org/10.1016/S00323861(01)00086-6.

9. Martino, V. P., Jiménez, A., \& Ruseckaite, R. A. (2009). Processing and characterization of poly(lactic acid) films plasticized with commercial adipates. Journal of Applied Polymer Science, 112(4), 2010-2018. http://dx.doi.org/10.1002/ app. 29784

10. Liu, H., \& Zhang, J. (2011). Research progress in toughening modification of poly(lactic acid). Journal of Polymer Science. Part B, Polymer Physics, 49(15), 1051-1083. http://dx.doi. org/10.1002/polb.22283.

11. Jamshidian, M., Arab Tehrany, E., Cleymand, F., Leconte, S., Falher, T., \& Desobry, S. (2012). Effects of synthetic phenolic antioxidants on physical, structural, mechanical and barrier properties of poly lactic acid film. Carbohydrate Polymers, 87(2), 1763-1773. http://dx.doi.org/10.1016/j.carbpol.2011.09.089.

12. Burgos, N., Tolaguera, D., Fiori, S., \& Jimenéz, A. (2014). Synthesis and characterization of lactic acid oligomers: Evaluation of performance as poly(lactic acid) plasticizers. Journal of Polymers and the Environment, 22(2), 227-235. http://dx.doi.org/10.1007/s10924-013-0628-5.

13. Kfoury, G., Raquez, J. M., Hassouna, F., Odent, J., Toniazzo, V., Ruch, D., \& Dubois, P. (2013). Recent advances in high performance poly(lactide): from "green" plasticization to super-tough materials via (reactive) compounding. Frontiers in 
Chemistry, 1, 32-46. http://dx.doi.org/10.3389/fchem.2013.00032. PMid:24790960.

14. Mano, E. B., Dias, M. L., \& Oliveira, C. M. F. (2004). Quimica experimental de polímeros. São Paulo: Edgard Blücher.

15. Sarasua, J. R., Rodríguez, N. L., Arraiza, A. L., \& Meaurio, E. (2005). Stereoselective crystallization and specific interactions in polylactides. Macromolecules, 38(20), 8362-8365. http:// dx.doi.org/10.1021/ma051266z.

16. Silverstein, G. C., Bassler, T. C., \& Morrill, R. M. (1991). Spectrometric identification of organic compounds. New York: Wiley.

17. Byun, Y., Whiteside, S., Thomas, R., Dharman, M., Hughes, J., \& Kim, Y. T. (2012). The effect of solvent mixture on the properties of solvent cast polylactic acid (PLA) film. Journal of Applied Polymer Science, 124(5), 3577-3582. http://dx.doi. org/10.1002/app.34071.

18. Liu, D. Y., Yuan, X. W., Bhattacharyya, D., \& Easteal, A. J. (2010). Characterisation of solution cast cellulose nanofibrereiforced poly(lactic acid). Express Polymer Letters, 4(1), 26-31. http://dx.doi.org/10.3144/expresspolymlett.2010.5.

19. Lucas, E. F., Soares, B. G., \& Monteiro, E. (2001). Caracterização de polímeros: determinação de peso molecular e análise térmica. Rio de Janeiro: E-papers.

20. Al-Obaidi, H., Lawrence, M. J., Al-Saden, N., \& Ke, P. (2013). Investigation of griseofulvin and hydroxypropylmethyl cellulose acetate succinate miscibility in ball milled solid dispersions. International Journal of Pharmaceutics, 443(1-2), 95-102. http:// dx.doi.org/10.1016/j.ijpharm.2012.12.045. PMid:23299082.

21. Martino, V. P., Ruseckaite, R. A., \& Jiménez, A. (2006). Thermal and mechanical characterization of plasticized poly (1-lactide-co-d,l-lactide) films for food packaging. Journal of Thermal Analysis and Calorimetry, 86(3), 707-712. http:// dx.doi.org/10.1007/s10973-006-7897-3.

22. Monteiro, E. E. C., \& Mano, E. B. (1984). Infrared study on the interaction of poly(vinyl chloride) and ketones. I. PVC-MEK film system. Journal of Polymer Science. Part A, Polymer Chemistry, 22(3), 533-545. http://dx.doi.org/10.1002/ pol.1984.170220303.

23. Van Krevelen, D. W. (1997). Properties of polymers. Netherlands: Elsevier Science. http://dx.doi.org/10.1016/B978-0-444-828774.50008-1.

24. Souza, D. H. S. (2011). Nanocompósitos de poli(ácido lácico)/ mica sintética: preparação e avaliação de morfologia e propriedades fisicas (Tese de doutorado). Universidade Federal do Rio de Janeiro, Rio de Janeiro.

25. Rabello, M. S. (2000). Aditivos de polímeros. São Paulo: Artliber.

26. Huda, M. S., Yasui, M., Mohri, N., Fujimura, T., \& Kimura, Y. (2002). Dynamic mechanical properties of solution-cast poly(Llactide) films. Materials Science and Engineering A, 333(1-2), 98-105. http://dx.doi.org/10.1016/S0921-5093(01)01834-2.

27. Wang, Y., Qin, Y., Zhang, Y., Yuan, M., Li, H., \& Yuan, M. (2014). Effects of N-octyl lactate as plasticizer on the thermal and functional properties of extruded PLA-based films. International Journal of Biological Macromolecules, 67, 58-63. http://dx.doi.org/10.1016/j.ijbiomac.2014.02.048. PMid:24598202.

Received: July 12, 2017

Revised: Nov. 13, 2017

Accepted: Jan. 04, 2018 